\title{
Determination of Classification Parameters of Barley Seeds Mixed with Wheat Seeds by using ANN
}

\author{
Kadir Sabanci \\ Department of Electrical and Electronics Engineering, Batman University \\ Batman, Turkey \\ kadir.sabanci@batman.edu.tr \\ Cevat Aydin \\ Department of Agricultural Machinery, Selçuk University \\ Konya, Turkey
}

\begin{abstract}
One of the basic problems that cause loss of yield in wheat is weed seeds that mixed with wheat seeds. In this study, discrimination of barley seed which mixed with wheat seeds has been realized. Classification of wheat and barley seeds has been achieved by using artificial neural network and image processing techniques. In the study, image processing techniques and the use of artificial neural network have been made possible with Matlab software. By using Otsu method, histogram data of seed images that were taken from web camera was obtained. By using histogram data, with multi-layered artificial neural network model, the system was educated and classification was made. Besides, wheat and barley seeds in the picture info where mixed seeds taken from the web camera exist were counted.
\end{abstract}

Keywords: Artificial Neural Networks, Systems Security, Seed Images

Received: 8 October 2018, Revised 4 January 2019, Revised 28 January 2019

DOI: $10.6025 /$ isej/2019/6/1/21-25

(C) 2019 DLINE. All Rights Reserved

\section{Introduction}

Quality is one of the important factors in agricultural products marketing. Grading machines have great role in quality control systems. The most efficient method used in grading machines today is image processing.

Digitisation of the image is the process in which the image in the camera is converted to electrical signals with optical - electrical mechanism [1].

Image processing, as a general term, is manipulation and analysis of the pictorial information [2].

Image processing techniques are used in different areas such as industry, security, geology, medicine, agriculture. Image processing and artificial neural networks are used in agriculture in fruit color analysis and classification, root growth monitoring, 
measurement of leaf area, determination of weeds $[3,4,5,6,7]$.

Artificial neural networks is an information processing system which have been exposed with inspiration of biological neural networks and includes some similar performance characteristics to biological neural networks [8]. Simply, ANN that imitates the function of the human brain has several important features such as learning from data, generalizing, working with an unlimited number of variables etc.

It is seen that ANN is used in crop production, which constitutes an important field of agriculture engineering, in identification and classification stages of a wide range of agricultural products such as grape, wheat, peppers and olives [9].

In this study, a software has been developed for distinguishing the wheat and barley seeds which has been mixed during harvesting. Wheat and barley seeds which has been mixed, have been attempted to distinguish by using image processing techniques and artificial neural networks. Multilayer artificial neural networks has been performed for the process to be more precise and faster. System has been trained by using barley and wheat seeds pictures. Wheat and barley seeds have been classified successfully by using improved system. This study exemplifies image processing and artificial neural networks in agriculture.

\section{Material Method}

In this study, image of wheat and barley seeds photos have been taken by using a webcam with 1.3 MP (Mega Pixels) and having CCD sensor. Usage of image processing and artificial neural networks are provided by Matlab. In this study, 50 wheat seeds, 50 barley seeds were used. Black background is used at the stage of image processing for faster and correct results.

Firstly, wheat and barley seeds image information was received to obtain image informations that was to enter to Artificial neural networks. Picture information of wheat and barley seeds are shown in Figure 1.

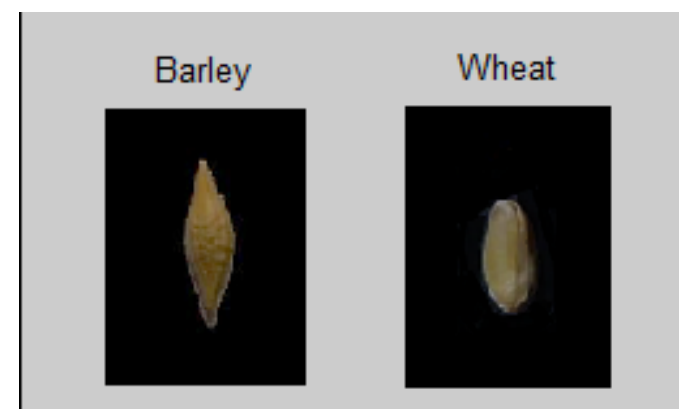

Figure 1. Wheat and barley seeds

Wheat and barley seeds image information was converted to gray level images. Filtration was performed to pictures tor reduce noise and interference. Wheat and barley seeds pictures which were converted into gray levels are shown in Figure 2.

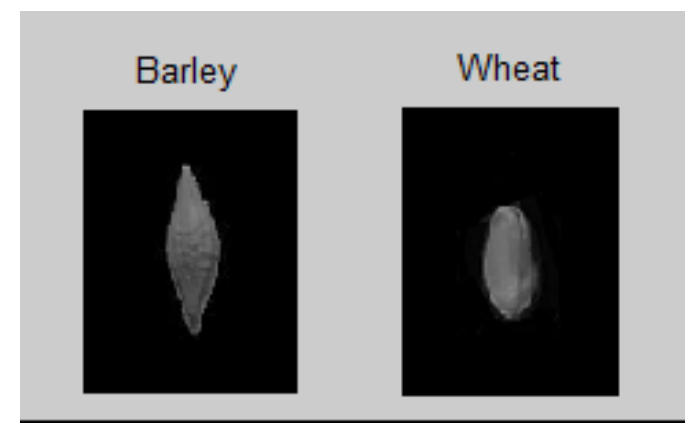

Figure 2. Gray level images belong to wheat and barley seeds 
Image information which is at gray level were converted to black and white picture by using Otsu method. Otsu algorithm provides the clustering of these pixels according to the distribution of pixel values in the image. Thresholding process is one of the important processes in image processing. Especially, this method is used for highlighting closed and discrete areas of the object in the image. It includes the arrangement of image which was divided into pixels until to the image in dual structure. Simply, thresholding process is a process of discarding pixel values on the image according to specific values, and replacing other value / values. Thus determination of object lines and backgrounds of the object on the image were provided [10]. Threshold value is determined by using Otsu method. if it is under this value, pixels are converted to 0 value; if it is over this value pixels are converted to 1 value. Wheat and barley seeds pictures in black and white pictures are shown in Figure 3.

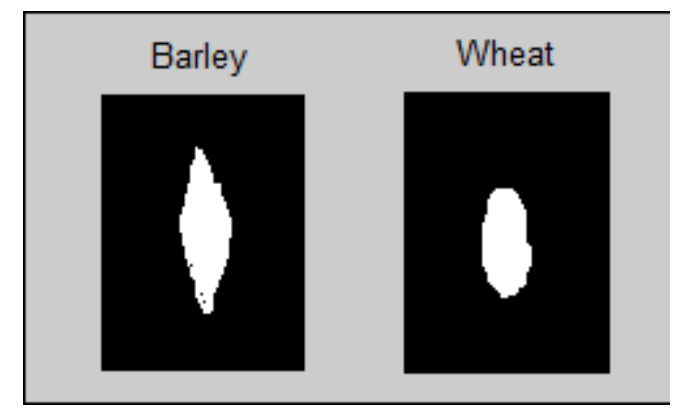

Figure 3. Binary image information belong to wheat and barley seeds

In this study, Matlab Software's Artificial Neural Network toolbox were used to distinguish wheat and barley seeds. ANN 's main tasks are to learn structure in the model data set, to make generalizations in order to fulfill to required task. To make this, the network is trained with the samples of related event to make generalization. Multi-layered artificial neural networks are the most commonly used in ANN models.

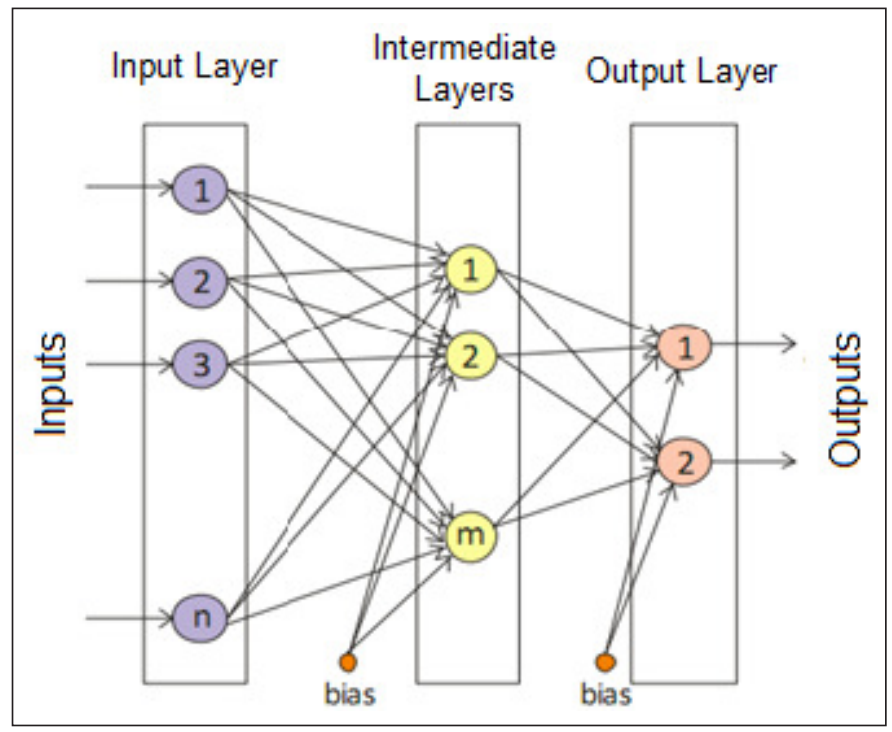

Figure 4. Multi-layered artificial neural network

In the study, neural network model with multilayer, feedforward, back propagation was used. Multilayer Perceptron (MLP) networks are a feedforward neural network model which has different number of neurons in the input layer, an intermediate layer consisting of one or more layers(s) and consisting of output layer. The structure of MLP neural network is shown in Figure 4. MLP neural network outputs of the neurons in a layer are connected to all input of the neurons with weights. The number of neurons in the input and output layer is determined according to the implementation problems. The number of intermediate layers, number of neurons in the intermediate layer and activation function are determined by the designer by trial and error method [11]. 
Segmentation process was performed by using digital image processing techniques on images belonging to mixed wheat and barley seeds and by determining the place of each seeds on the picture. Each pistachios was cropped in 100x100 pixels size. First of all, digital images of each seeds were converted to gray level images.

Picture was filtered in order to remove noise and very small objects (dust, etc..). Noise removed gray level pictures was converted to black and white picture by using Otsu method. data sets, which will enter to ANN, will be created by converting black and white picture informations in 100x100 size of each seeds to column matrix.

\section{Conclusion}

Classification process with MLP model average success of the test was determined \%100 in the structure, where 100 neurons are used, in the hidden layer. When creating the MLP structure, neurons in the hidden layer and output layer activation function was used as logarithmic sigmoid. The error back-propagation was used in training of the ANN model algorithm and network was trained 250 steps. The results which was obtained in classification by using MCA process are presented in Table 1.

\begin{tabular}{|c|c|c|c|}
\hline $\begin{array}{l}\text { Number Of Neurons in } \\
\text { Hidden Layer }\end{array}$ & \multicolumn{3}{|c|}{ Classification success (\%) } \\
\hline 25 & Wheat seeds & Barley seeds & Average success \\
\hline 50 & 44 & 48 & 92 \\
\hline 75 & 45 & 49 & 94 \\
\hline 100 & 47 & 49 & 96 \\
\hline
\end{tabular}

Table 1. Classification results with using MCA process

In this study, gray level images information of wheat and barley seeds by using image processing techniques. Afterwards, the system was trained by using Otsu Method, by converting binary picture information, by using multilayer neural network model. Then, in the realized system, the distinguishing of mixed wheat and barley seeds was performed.

System can be developed by using moving band and camera system and distinguishing of wheat and barley seeds can be carried out in real-time. Also, packaging process of seeds in a certain number can be performed. This study is an example of using image processing and neural network in agricultural field.

\section{References}

[1] Yaman, K. (2000). Görüntü i_leme yönteminin Ankara h1zl1 rayl1 ula_1m sistemi güzergah1nda sefer araliklarinin optimizasyonuna yönelik olarak incelenmesi. Yaylnlanmam1_Yüksek Lisans Tezi, Gazi Üniversitesi, Fen Bilimleri Enstitüsü.

[2] Castelman, R. K. (1996). Digital image processing. Prentice hall, Englewood Cliffs, New Jersey, USA. Neuman, M. R., H. D. Sapirstein, E. Shwedyk and W. Bushuk. 1989. Wheat grain colour analysis by digital image processing. II. Wheat class discrimination. Journal of Cereal Science 10. 183-188.

[3] Keefe, P. D. (1992). A Dedicated wheat grain image analyzer. Plant Varieties and Seeds 5. 27-33.

[4] Trooien, T. P., Heermann, D. F. (1992). Measurement and simulation of potato leaf area using image processing. Model development. Transactions of the ASAE, 35 (5) 1709-1712.

[5] Pérez, A. J., Lopez, F., Benlloch, J. V., Christensen, S. (2000). Colour and shape analysis techniques for weed detection in cereal fields. Computers and Electronics in Agriculture, 25. 197-212.

[6] Dalen, G. V. (2004). Determination of the size distribution and percentage of broken kernels of rice using flatbed scanning and 
image analysis. Food Research International, 37. 51-58.

[7] Jayas, D. S., Karunakaran, C. (2005). Machine vision system in postharvest technology. Stewart Postharvest Review, 22.

[8] Fausett, L. (1994). Fundamentals of Neural Networks: Architectures, Algorithms and Applications, Prentice Hall.

[9] Kavas, G., Kavas, N. (2012). G1 dalarda yapay sinir alar1 ve bulan1k mant1k. DÜNYA yay1nc111k, GIDA Dergisi 2012-01. 9396.

[10] Yaman, K., Sarucan, A., Atak, M., Aktürk, N. (2001). Dinamik çizelgeleme için görüntü i_leme ve ARIMA modelleri yard1m1yla veri haz1rlama. Gazi Üniv. Müh. Mim. Fak. Dergisi, 16 (1) 19-40.

[11] Öztemel, E. (2003). Yapay Sinir Alari. Istanbul: Papatya Yaylncilik. 